\title{
Evaluation of Austin Moore prosthesis in the femur neck fracture management: Retrospective study
}

\author{
Hirabhai Patel K. ${ }^{1}$, Pitambardas Patel P. ${ }^{2 *}$ \\ DOI: https://doi.org/10.17511/ijoso.2020.i04.08 \\ ${ }^{1}$ Kalpesh Hirabhai Patel, Assistant Professor, Department of Orthopedics, Banas Medical College, Palanpur, Gujarat, India. \\ 2* Pravinkumar Pitambardas Patel, Assistant Professor, Department of Orthopedics, Banas Medical College, Palanpur, Gujarat, India.
}

Introduction: Femoral neck fractures have been considered unsolvable fractures 'in the older era of orthopedics due to the high rate of associated complications, which include non-union and avascular necrosis of the femoral head, among others. The aim of the study was to assess the functional outcome following the use of Austin Moore prosthesis in the elderly population and to substantiate the use of AMP in modern-day orthopedic practice. Materials and Methods: A total of 40 patients were included in the study. The patients who were more than 60 years of age, those were not having any major hip surgery or problem before the fracture; all those who were treated with Austin prosthesis were included in the study. Results: The patients were graded as excellent, good, fair, and poor depending on the functional outcome of the study based on each of the criteria for the assessment of the hip. The score range from 30 to 95 in the present study. Good to excellent results were obtained in around $45 \%$ of patients, satisfactory results were obtained in $30 \%$ and the poor result was obtained in $25 \%$ patients. Conclusion: Hemiarthroplasty with Austin Moore Prosthesis for fracture neck of femur gives fairly good long term functional outcome in elderly patients. Patients are, for the most part, without pain. Even if there, pain is usually not disabling and doesn't affect routine ambulation, except when the prosthesis is loose or there is acetabular erosion. These complications are the exception rather than the norm.

Keywords: Austin Prosthesis, Fracture neck of femur, Functional outcome, Quality of life

Corresponding Author

Pravinkumar Pitambardas Patel, Assistant Professor, Department of Orthopedics, Banas Medical College, Palanpur, Gujarat, India.

Email: parthorthopaedic@yahoo.com
How to Cite this Article

To Browse

Patel KH, Patel PP. Evaluation of Austin Moore prosthesis in the femur neck fracture management: Retrospective study. Surgical Rev Int J Surg Trauma Orthoped. 2020;6(4):265-269.

Available From

https://surgical.medresearch.in/index.php/ijoso/artic le/view/195

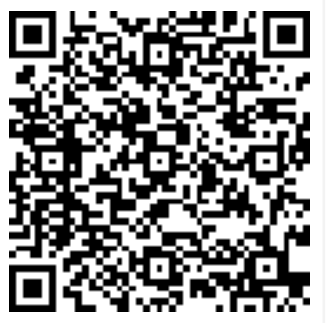

Manuscript Received 2020-07-15

Conflict of Interest No

Review Round 1
2020-07-31
Funding
Nil

(c) 2020 by Kalpesh Hirabhai Patel, Pravinkumar Pitambardas Patel and Published by Siddharth Health Research and Social
Welfare Society. This is an Open Access article licensed under a Creative Commons Attribution 4.0 International License Welfare Society. This is an Open Access article licensed under a Creative Commons Attribution 4.0
https://creativecommons.org/licenses/by/4.0/ unported [CC BY 4.0].
Accepted 2020-08-26 2020-08-14

Review Round 3

Note 


\section{Introduction}

People in this age group suffer from numerous illnesses that can aggravate the morbidity following fractures and complicate the treatment of these fractures. The treatment goal is to return the patient to his or her pre-morbid status of function [1]. A fracture of the hip is a common injury. With increasing life expectancy throughout the world, the number of elderly individuals is increasing in every geographical area. According to the Swedish national hip fracture register, intracapsular fractures of the femoral neck constitute $53 \%$ of all hip fractures out of which $33 \%$ is undisplaced and $67 \%$ is displaced [2].

Osteoporosis, co-morbidities, increased incidence of trivial trauma increases the incidence and complicates the treatment of these fractures. This high incidence is due to weak bones and increased incidence of trivial trauma [3] The treatment goal is to return the patient to his or her pre-morbid status of the function. An increase in the average lifespan and improved medical facilities have greatly increased the incidence of these fractures [4].

The blood supply of the neck and head of the femur is extensive, intricate, and complicated. The healing process mainly depends on good blood supply. This further handicap the treatment of these fractures and the healing process is always in doubt. Under such circumstances one has to decide whether the prolonged immobilization has to be employed to achieve the bony union or quick ambulation by Hemi replacement arthroplasty, to achieve a fair degree of function [5].

Management of femoral neck fractures in elderly patients has been controversial. Femoral neck fractures have been considered unsolvable fractures' in the older era of orthopedics due to the high rate of associated complications, which include nonunion and avascular necrosis of the femoral head, among others [6]. Austin Moore prosthesis, historically, has served as a good implant over the years in the management of femoral neck fracture in the elderly. There are many case reports of these actually lasting a long time ( $>20$ years). The disadvantages of AM prosthesis are relatively poor outcomes inactive patients secondary to poor femoral fixation and a marked potential for acetabular erosion [7].

In the elderly population, when the cost of treatment and potential complications of modern hip
Prostheses are considered, it appears wise to limit the use of bipolar and total-hip arthroplasties to patients who are most likely to benefit from them [8]. In fact, many patients will not survive long enough after their hip fracture to justify procedures with higher risk and higher costs. Moreover, studies on the functional outcomes of AMP vs Bipolar prosthesis have shown the end result to be the same. Thus, the need for a study was required which can help to assess the functional outcome following the use of Austin Moore prosthesis in the elderly population and to substantiate the use of AMP in modern-day orthopedic practice. The present study was undertaken with the above objectives in mind.

\section{Materials and Methods}

Study Design and Study Setting: This is the retrospective study conducted on the individuals who were admitted with complaints of fracture of the femure's neck. The study patients were followed for the postoperative assessment of the quality of life in the patients. The study was carried out to evaluate the functional end results of Austin Moore Hemiarthroplasty for the fracture neck of femur in the elderly. Ethical approval was taken from the institutional ethical committee and written informed consent was taken from all the participants.

Inclusion Criteria: Patients with femur neck fractures who were admitted to the medical hospital were included in the study. All the patients were operated with Austin Prosthesis. The patients who were more than 60 years of age, those were not having any major hip surgery or problem before the fracture; all those who were treated with Austin prosthesis were included in the study.

Exclusion Criteria: Patients with fracture of the femur but treated with another treatment, patients with pathological fracture of the femur.

Methodology: A total of 40 patients were included in the study. All the patients who were included in the study were followed for a certain period of time. Those who were not able to come for the follow-up, house visits were arranged and the progress was assessed for assessment of the quality of life. All the details at the time for follow up were recorded in the follow-up chart. Wherever possible, a follow-up radiograph of the pelvis was obtained to assess the status of the prosthesis in situ.

The Harris hip scoring system was used to see the functional outcome. Based on the points scored of 
Total 100 the patients were allotted a score. The grading system is as follows: if the score is between 91 - 00: Excellent, If score between 81-90: Good, if score between 71- 80: Fair, if the score is below 70: Poor.

The medial femoral offset in the hip region where Austin Moore prosthesis was implanted, was measured on follow up. These measurements were compared with the variation of offset measurement of the uninvolved hip in the study population.

Such measurements could be carried out for only those patients in whom radiographs, obtained either immediately after surgery or at follow up showed comparable hip position and alignment of both hips. The femoral offset was calculated by measuring the perpendicular distance from the center point of the femoral head to a line bisecting the length of the femur.

Statistical analysis: The recorded data was compiled and entered in a spreadsheet computer program (Microsoft Excel 2007) and then exported to the data editor page of SPSS version 15 (SPSS Inc., Chicago, Illinois, USA). For all tests, confidence level and level of significance were set at $95 \%$ and $5 \%$ respectively.

\section{Results}

A total of 40 patients who underwent surgery for correction of fracture of the neck of the femur were included in the study. The minimum age of the patients included in the study was 60 years and the maximum age was 88 years. The mean age of male in the study was found to be 71 years and that in females were found to be 73 years.

The onset of the fracture was seen due to various reasons in the study. Maximum cases (24) were of injuries due to falling or slipping on the floor of the house. Fall from height reason was seen in 10 cases. The reason for roadside traffic accidents was seen in 4 patients and the reason for a stress fracture was seen in two patients (Table 1 ).

Table-1: Mode of injury in the patients.

\begin{tabular}{|l|l|}
\hline \multicolumn{1}{|c|}{ Mode of injury } & \multicolumn{1}{c|}{ No. of patients } \\
\hline Fall of height & 10 \\
\hline Trauma from slipping & 24 \\
\hline Stress fracture & 2 \\
\hline Road traffic accident & 4 \\
\hline Total & 40 \\
\hline
\end{tabular}

As per the amount of pain and its relation to daily
Activity, the patients included in the study were given the score. No pain or minimal pain was found in 32 patients. Moderate pain that affects the daily activity was seen in 8 patients. None of the patients experienced any type of pain when they were lying on the bed.

The support required for walking was assessed on follow up. A total of 10 patients did not require any type of support for walking. Cane for the long walk was required in 12 patients, another 10 patients require a cane for most of the time, there were 4 patients who required a walker for walking and there were 4 patients who were unable to walk.

The distance covered by walking was also assessed. There were 8 patients who were able to walk for an infinite distance. Up to $1 \mathrm{~km}$ was covered by 8 patients; $0.5 \mathrm{~km}$ was covered by 12 patients, while in 8 patients they were confined only indoors. There were 4 patients who were on best rest or require a wheelchair for walking.

The patients were graded as excellent, good, fair, and poor depending on the functional outcome of the study based on each of the criteria for the assessment of the hip. The score range from 30 to 95 in the present study.

The excellent score was obtained in 6 patients, 12 patients had a good score, a fair score was found in 12 patients and 10 patients had a poor score. Good to excellent results were obtained in around $45 \%$ of patients, satisfactory results were obtained in $30 \%$ and the poor result was obtained in $25 \%$ patients.

Table-2: Final functional outcome in the patient's after a hip surgery.

\begin{tabular}{|l|l|l|}
\hline \multicolumn{1}{|c|}{ Harris hip score } & \multicolumn{1}{c|}{ Grading } & \multicolumn{1}{c|}{ Frequency } \\
\hline$<70$ & Poor & 10 \\
\hline $71-80$ & Fair & 12 \\
\hline $81-90$ & Good & 12 \\
\hline $91-100$ & Excellent & 6 \\
\hline Total & 40 \\
\hline
\end{tabular}

Horizontal femoral offset measurements were taken in 20 patient radiographs, in which comparable views of both the hip joints were obtained. This included 6 immediate post-op and 14 follow up $X$ rays.

Both the operated hip and uninvolved hip were assessed. Offset values were found to be $8.07 \%$ greater for the hips operated with Austin Moore hemiarthroplasty. 


\section{Discussion}

Management of fracture of femoral neck still remains major and difficult undertaking for an orthopedic surgeon. The pendulum of treatment modality is swinging between reduction and internal fixation with various supplementary methods as osteosynthesis to total hip replacement [9]. The final goal in replacement surgery of fracture neck femur is an early return to daily activities to prefracture levels. This is particularly applicable to the elderly age group where complications related to prolonged immobilization need to be prevented.

The present study was done with 40 patients included with the aim to assess the femur neck fracture treatment with Austin Moore Prosthesis in elderly patients. The observations were noted and the analyses were made. The results of the present study were evaluated with studies done by other authors. Various aspects of the results have been observed and discussed in detail keeping in view the living condition of an average Indian.

The majority of the patients had a good range of hip motion ( $>160$ degrees). The majority of the patients were able to walk for a considerable distance ( $1 \mathrm{~km}$ and beyond). Regarding the use of walking support, a cane was the most commonly employed walking aid in those patients who required one. In a similar series, Stinchfield et al [10] (1957) reported $14 \%$ of their patients using cane regularly. $16 \%$ of Ban and Donovan [11] (1964) series were using the cane always, $34 \%$ were using occasionally and $20 \%$ discarded it. Saraf and Saxena (1978) reported $52.7 \%$ of patients using cane regularly, $23.1 \%$ occasionally and $21.8 \%$ were not using it.

At the end of the present study, using the criteria elicited in the Harris Hip Scoring system, $45 \%$ of the hips were classified as having good to excellent results, $30 \%$ of patients had a satisfactory result and $25 \%$ of the patients had a poor result. There are various similar studies in the International literature assessing functional outcomes following AMP hemiarthroplasty for fractured neck of femur in the geriatric population [12].

The one major finding at the end of the present study deserving attention is the relatively high incidence of Poor functional outcome ( $25 \%$ cases) [13]. Arwade [14] (1987) attributed the poor results to complications during or following surgery. In the 10 pelvis radiographs where horizontal femoral offsets were measured, offset values were found to
Be $8.07 \%$ greater in the hips operated with Austin Moore hemiarthroplasty. A difference in the femoral offset postoperatively is often the result of the larger neck-shaft angle of the prosthesis than the patient's own anatomy. The femur moves closer to the pelvis and reduces both the range of movement and the tension surrounding soft 95 tissues. A low femoral offset can lead to wearing of the acetabular cup which is the primary cause of aseptic loosening, abnormal gait, joint instability, and dislocation

Prospective multi-center studies are needed to further evaluate the safety and efficacy of this treatment alternative.

\section{Conclusion}

Hemiarthroplasty with Austin Moore Prosthesis for fracture neck of femur gives fairly good long term functional outcome in elderly patients. Patients are, for the most part, without pain. Even if there, pain is usually not disabling and doesn't affect routine ambulation, except when the prosthesis is loose or there is acetabular erosion. These complications are the exception rather than the norm.

\section{What does the study add to the existing knowledge}

Austin Moore hemiarthroplasty is a frequently done and well-accepted procedure which has a good functional outcome with the low cost of the implant compared to bipolar and total hip arthroplasty

\section{Author's contribution}

Dr. Kalpesh Hirabhai Patel: Formulated the aims and objectives with study design and helped in data collection from the medical record department.

Dr. Pravinkumar Pitambardas Patel: Contributed to the preparation of the manuscript and data analysis.

\section{Reference}

01. Murphy K, Barkley RA. Attention deficit hyperactivity disorder adults- comorbidities and adaptive impairments. Comprehens Psychiat. $1996 ; 37(6) 393-401$.

[Crossref]

02. Arwade D. A review of internal fixation and prosthetic replacement for fresh fractures of the femoral neck. Clini Orthop India. 1987;1;77-82. [Crossref] 
03. Marya S, Thukral R, Singh C. Prosthetic replacement in femoral neck fracture in the elderly- Results and review of the literature. Indian J Orthopaed. 2008;42(1)61.

[Crossref]

04. Gjertsen J-E, Engesæter LB, Furnes O, Havelin LI, Steindal K, Vinje T, et al. The Norwegian Hip Fracture Register- experiences after the first 2 years and 15,576 reported operations. Acta orthopaedica. 2008;79(5)583-593.

[Crossref]

05. Daniel M, Mohammed S, Francis A, William $Y$, Joseph K, Cornilius E. Early result of hemiarthroplasty in elderly patients with fracture neck of femur. Nigerian Med $\mathrm{J}$. $2015 ; 56(1) 64$.

[Crossref]

06. Marottoli RA, Berkman LF, Cooney Jr LM. Decline in physical function following hip fracture. J Am Geriatr Soc. 1992;40;861-866.

[Crossref]

07. Stinchfield FE, Cooperman B, Shea JR CE. Replacement of the femoral head by Judet or Austin Moore prosthesis. JBJS. 1957;39(5)10431058.

[Crossref]

08. Rogmark C, Johnell O. Orthopaedic treatment of displaced femoral neck fractures in elderly patients. Disabil Rehabilitat. 2005;27(1819)1143-1149.

[Crossref]

09. Bhosale P, Suryawanshi A, Mittal A. Total hip arthroplasty for failed aseptic Austin Moore prosthesis. Indian J Orthopaed. 2012;46;297303.

[Crossref]
10. Kailash S. Radiological assessment of interprosthetic joint movement in bipolar hip hemiarthoplasty for fracture neck of femur. PSG Institute of Medical Sciences and Research, Coimbatore. 2014.

[Crossref]

11. Barr JS, Donovan JF, Florence DW. Arthroplasty of the hip- theoretical and practical considerations with a follow-up study of prosthetic replacement of the femoral head at the Massachusetts General Hospital. JBJS. $1964 ; 46(2) 249-266$.

[Crossref]

12. Fernández-Valencia J, Llobet $F$, Pons $N$, LópezZabala I, Gallart X, Bori G, Riba J. Intraoperative Periprosthetic Femoral Fractures Related to Austin Moore Hemiarthroplasty-A Retrospective Review of 365 Patients. Sci Res. 2013.

[Crossref]

13. Langton D, Jameson S, Joyce T, Hallab N, Natu $\mathrm{S}$, Nargol A. Early failure of metal-on-metal bearings in hip resurfacing and large-diameter total hip replacement- a consequence of excess wear. J Bone Joint Surg. 2010;92(1)38-46.

[Crossref]

14. Deo SS, Herode PG, Shroff A, Mandlewala V, Yadav K. Study of Fracture Neck Femur Treated with Cemented Bipolar Prosthesis vs Austin Moore Prosthesis in Elderly. J Pharmaceuti Biomed Sci. 2015;5(12).

[Crossref] 